\title{
DE LA MUJER A LA VIRGEN MARÍA: DESPLAZAMIENTO SEMÁNTICO DE LA FIGURA FEMENINA
}

\author{
Dilia Flórez Díaz, Nelly García Gavidia y Diana Bohórquez \\ Universidad de Zulia (Venezuela)
}

\section{RESUMEN}

En el artículo se presentan los resultados parciales de una investigación sobre los cultos patronales católicos a las advocaciones marianas en el occidente venezolano, en dos ciudades del país: Maracaibo y Barquisimeto. Se describe, analiza e interpretan los cultos a: Nuestra Señora del Rosario de Chiquinquirá y La Divina Pastora; haciendo referencia a las creencias precoloniales, a su origen colonial, y a su resemantización en el presente. Se aplica el análisis del discurso a los relatos, cantos y narrativas recogidas en la experiencia de campo y se relacionan con las representaciones que de la mujer se tienen en ambos lugares. Se concluye que entre los creyentes existe un desplazamiento semántico de la mujer o figura femenina a la Virgen-Madre.

PALABRAS CLAVE: mujer, femenino, madre, vírgenes, Zulia, Lara, Venezuela.

\section{ABSTRACT}

From woman to Virgin Mary: semantic displacement of the female figure

This article presents the partial results of a research about catholic patronal cults, by presenting the case of marian devotions of western Venezuela, specifically in two major cities of the country: Maracaibo and Barquisimeto. It describes, analyzes and interprets the cult of two virgins: Nuestra Señora del Rosario de Chiquinquirá y 
La Divina Pastora, by making reference to precolonial beliefs, to its colonial origin, and specially to its resemanticization in the present. It applies discourse analysis to the stories, chants and narratives about these deities, collected during field work, and also it links them up with representations of women observed in both places. This work concludes that within the believers there is a semantic displacement from the woman or female figure to the Mother-Virgin.

KEY WORDS: woman, female, mother, virgins, Zulia, Lara, Venezuela

\section{INTRODUCCIÓN}

Durante los procesos de conquista y colonización, como práctica asimiladora y proselitista, la Iglesia Católica, adaptó las prácticas y creencias cristiano-católicas a los diferentes y nuevos auditorios. Un ejemplo de ello, fue darle prioridad a los cultos a la Virgen María, deidad cristiana mediadora entre Dios y los hombres y que tenía todas las posibilidades -como de hecho lo fue- de ser asimilada a las deidades amerindias, originándose así, en un primer momento, una yuxtaposición de símbolos sagrados que se extendió a toda las Américas y que más tarde, en la convivencia, convirtió a la Virgen María y sus advocaciones, frecuentemente ligadas a un territorio (barrio, sector, localidad, nación, región, país), como uno de los símbolos religiosos más extendido. Citemos como ejemplo: a la Virgen de Coromoto, la Virgen del Valle, La Virgen de Guadalupe, la Virgen de la Paz, la Virgen de Luján, Nuestra Señora Aparecida, Nuestra Señora del Carmen, Nuestra Señora del Pilar, por nombrar algunas. Pudiera pensarse que en cada una de estas advocaciones de la "Virgen María" se encuentra presente la transmutación de antiguas divinidades femeninas, tal como lo afirmara Octavio Paz ${ }^{1}$, cuando señalaba que... "La Virgen fue y es algo más, y de ahí que haya sobrevivido al proyecto histórico de los criollos. La Virgen es el punto de unión de criollos, indios y mestizos y ha sido la respuesta a la triple orfandad: la de los indios porque Guadalupel Tonantzin es la transfiguración de sus antiguas divinidades femeninas; la de los criollos porque la aparición de la Virgen convirtió a Nueva España en una madre más real que la de España; la de los mestizos porque la Virgen fue y es la reconciliación con su origen y fin de su legitimidad".

En los supuestos de los cuales partimos no existe la aceptación a priori de considerar que hay una representación universal de la Gran Diosa o Diosa madre, como algunos historiadores de las religiones lo señalaron en la segunda mitad del siglo pasado. Reconocemos la particularidad histórica y cultural de cada uno de los contextos y la dinámica diferenciada de los procesos de cambios culturales que en cada una de las regiones se dieron a partir del contacto entre los diversos grupos humanos.

En el caso de la sociedad venezolana, los resultados de la investigación arqueológica, en diferentes regiones del país, nos muestra una gran cantidad de figuras femeninas de arcilla representadas de pie, o en posición sedente sobre las piernas o con ambas manos

1 PAZ, Octavio. Sor Juana Inés de la Cruz o las Trampas de la Fe. Six Barral. Barcelona, Six Barral, 1982, pp. 63-64. 
sobre éstas, con amplias caderas e indicaciones muy claras de sexo, extremidades gruesas (la llamada diosa de Tacarigua, las baubas, o las deidades ctónicas y felinescas). "Si llegase a tus manos una de esas estatuillas que dejó en Tacarigua el Arawaco de deformado cráneo, palpa... la pomposidad de sus caderas, el estiramiento doloroso de su vientre, el enarcamiento angustiado de sus cejas en función de la creación, y palpa también,... la menuda fragilidad de sus erguidos senos, apenas insinuados, por qué? Porque la mano alfarera quiso decir que aquella madre prosigue siendo virgen o proseguirá eternamente siendo madre" 2 .

Así, reproducciones de caderas, vagina, glúteos, representación de embarazos, posición de parto, vienen siendo representaciones que se encuentran plasmadas en los diferentes mitos fundacionales y los controles de la producción, ejercidos sobre las mujeres. Figuras que además, estarían simbolizando a la mujer en etapa fértil.

También la etnohistoria nos habla de la presencia de deidades femeninas: Yara en la región amazónica, Mma entre los wayuu, la madre de las aguas entre los a $\tilde{n} u$ de la Laguna de Sinamaica, entre otras. Además de algunos mitos y leyendas que han persistido y hablan igualmente de "diosas" o "dueñas de los lugares". En el Archivo General de la Nación ${ }^{3}$, se hace referencia al culto a una deidad femenina que se practicaba en la región centro occidental en el siglo XVIII que fue perseguido y atacado por las autoridades religiosas y políticas de la época ${ }^{4}$. En este caso son diosas - madres, incorporadas a la cosmogonía nacional.

Por otro lado, desde siglo XIX hasta nuestros días, ha existido una tendencia de la Iglesia Católica a promover el culto Mariano, considerada María Virgen como madre y esposa por excelencia. En el caso venezolano, el culto mariano se expresa en diversas advocaciones de la Virgen asociadas a territorios particulares y que sirvieron de mediación en la cristianización de los amerindios, dos ejemplos de ello son la Virgen de Coromoto que se le apareció a los indios Coromoto y la Virgen del Rosario del Paraute que apareció en el río Paraute a los indígenas que habitaban en su desembocadura en el Lago de Maracaibo.

Actualmente, en el país hay tres vírgenes que convocan y cohesionan a una parte importante de la población, sus centros de devoción están ubicados: al este, en la región oriental del país, (Estados Nueva Esparta, Sucre, Monagas y Anzoátegui) es el culto a Nuestra Señora del Valle; en la región centro-occidental, Edo. Lara y sus alrededores, que es el culto a la Divina Pastora y finalmente, en la región zuliana-región noroccidental del país- donde existe la devoción a Nuestra Señora del Rosario de Chiquinquirá.

Estos hechos nos han servido de estímulo para indagar sobre: a) la presencia en dos de las regiones del país, la centro occidental y la zuliana, de esa figura femenina representada como la Virgen - Madre; b) las características que tiene la resemantización que en el presente se hace de ésta, en esas dos regiones.

En el trabajo se describe, analiza e interpretan los cultos a estas dos vírgenes: Nuestra Señora del Rosario de Chiquinquirá y La Divina Pastora; haciendo referencia a las creencias precoloniales, a su origen colonial, y sobretodo a su resemantización y

2 ANTOLINEZ, Gilberto. Hacia el indio y su mundo. Barquisimeto, Universidad Centro Occidental Lisandro Alvarado, 1972, p. 26.

3 Archivo General de la Nación (tomos VII/165; VIII/20; XII/94).

4 GARCÍA GAVIDIA, N. Magie, religion et politique dans le culte de Maria Lionza, Le Vénézuela de 1948 à 1978. Memoire de l' École des Huates Etudes en Sciences Sociales, Paris. 1980. 
desplazamiento en el presente, que va desde la figura femenina hasta la Madre - Virgen. Aplicando el análisis del discurso a los relatos, cantos y narrativas recogidas en la experiencia de campo sobre estas deidades y relacionándolas con las representaciones que de la mujer se tienen en ambos lugares.

En Venezuela, así como en casi todos los países iberoamericanos, las representaciones simbólicas del panteón católico fueron plenamente aceptadas. La Virgen - María, ha sido uno de los miembros privilegiados de dicho panteón con la devoción de los diferentes grupos. Esta aceptación estuvo vinculada con el tipo de evangelización que se realizó durante la colonia, donde se privilegió la realización de las fiestas patronales. Éstas han cumplido diferentes funciones desde entonces: cohesionar a los múltiples grupos sociales y étnicos, canalizar los diversos intereses eclesiásticos, políticos y sociales, al mismo tiempo, que han servido para restaurar el sentido religioso, de compromiso y solidaridad entre los creyentes sin atender su pertenencia a etnia o clase.

En el caso que nos ocupa, en esta investigación, se trata de cultos con fiestas patronales vinculados a dos deidades femeninas que en la tradición católica representan a la mujer madre y a su caracterización, Virgen María: la Divina Pastora, en Santa Rosa del Cerrito ${ }^{5}$ (estado Lara), y de Nuestra Señora de Chiquinquirá en Maracaibo (estado Zulia). En los espacios geográficos donde se han desarrollado estas dos devociones la presencia indígena de los tiempos precoloniales dejó huella hasta el presente. En el caso de la Divina Pastora, toda la región de lo que hoy son los Estados Lara, Yaracuy y Portuguesa estuvo habitada por indios ayamanes, ciparicotos, caquetios, jirajaras, cuibas, achaguas, camagos, y gayones ${ }^{6}$. Y Nuestra Señora de Chiquinquirá es patrona de una región que

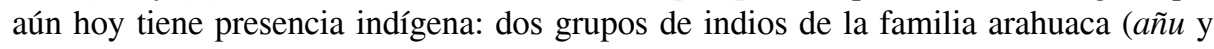
wayuu), dos de familia caribe (yu'kpa y xapreria) y uno chibcha (bari).

El culto y devoción a la Divina Pastora ${ }^{7}$, fue iniciado en Venezuela por los padres capuchinos que vinieron a América y se encargaron de la catequización en la región centro -occidental: La Divina Pastora formó parte de las enseñanzas capuchinas en las estrategias de la Iglesia Católica para catequizar a los indígenas. Una vez constituido el culto a la Divina Pastora en algunos pueblos fundados en territorios misionales de la región se les cambió el nombre y comenzó a aparecer el título pastoril de la Virgen. Ese fue el caso de Mapubares, fundado en 1693 y al cual los misioneros le dieron por título a la Divina Pastora en 1772; de la Divina Pastora de Jobal que fue como denominaron al antiguo pueblo de Lagunitas que había sido fundado en 1571; de la Divina Pastora de Boconó fundada en 1763 y de la Divina Pastora de Guanare Viejo en $1771^{8}$.

\footnotetext{
5 El pueblo de Santa Rosa del Cerrito fue fundado en Santa Rosa, entre los años de 1670 a 1691 con indios gayones. Así consta en una Real Cédula, expedida en Mérida el 6 de Abril de 1691, según Alfredo Jhan. 6 SUÁREZ, María Matilde/BETHANCOURT, Carmen. La Divina Pastora Patrona de Barquisimeto. Caracas, Fundación Bigott, 1996.

7 El culto a la Divina Pastora fue promovido por el sacerdote capuchino Isidoro de Sevilla, en Sevilla. El sacerdote a partir de una visión que tuvo, mandó a pintar la imagen de la Virgen -María en su labor de pastora y propuso para el culto tres requerimientos: Título de Pastora de las almas, atuendo pastoril y culto público. 8 CARROCERA, B. "Actuación de los capuchinos en la zona no misional de Venezuela durante el Período Hispano" Memoria del Tercer Congreso Venezolano de Historia Eclesiástica. Caracas, Editorial Arte, 1980. pp-73-119.
} 
Se cree que el culto a la nueva advocación fue traída a la provincia de Venezuela por el Prefecto de la Misión de los llanos, Marcelino de San Vicente en 1706. Este sacerdote predicó entre los gayones ${ }^{9}$ de las sabanas de Bobare y fundó en 1706 el pueblo Apostolado de Algaride al norte de Barquisimeto con un grupo de ellos. Al cabo de tres años entregó el pueblo al Obispo y éste lo dejó a cargo del doctrinero de Santa Rosa, Bartolomé de Salazar y Ruiz a quien se le considera el pacificador de estos indígenas.

Alrededor de 1670, ante la imposibilidad de someter a los Gayones $^{10}$, las poblaciones de Quibor, Carora y Nueva Segovia de Barquisimeto solicitaron al Cabildo, que convocaran a los misioneros capuchinos para que los pacificaran, éstos habían iniciado la misión de los llanos desde 1658. Esta misión fue la que tuvo mayor extensión territorial y el mayor número de pueblos; entre ellos, el de Santa Rosa del Cerrito o del Cerrillo lugar donde se realiza el culto a la advocación a la Divina Pastora.

La imagen de la Virgen, en la advocación de Pastora de almas, fue traída de Sevilla a Venezuela y por equivocación a Santa Rosa del Cerrito en la década entre 1715 - 24 y se le ubicó en la iglesia Santa Rosa de Lima. Con el pasar del tiempo se convirtió en la Patrona de la ciudad de Barquisimeto y de todo el estado Lara, dando origen así a una devoción popular que envuelve a cientos de miles de personas que acuden al templo en peregrinación durante todo el año y a su procesión el 14 de enero, cuando se conmemoran las fiestas patronales que se realizan desde hace 150 años, y que ha dado origen a un fenómeno colectivo difícilmente comparable con otras procesiones que tienen lugar en honor a otros miembros del panteón católico en Venezuela.

Para muchos, las primeras manifestaciones de la devoción a La Divina Pastora fueron emblemáticas de la gesta de la pacificación definitiva de los gayones, en el siglo XVIII. Dicha imagen se utilizó en las prédicas tanto para los feligreses como para los indígenas.

9 Una de las más antiguas referencias de los Gayones la hace Nicolás de Federmann, en los relatos de su viaje por Venezuela, publicados en su Historia Indiana (tomo II, pp. 181-184), quien los encuentra por primera vez en 1530 y los describe como indómitos. De igual manera puede afirmarse que conjuntamente con los ayamanes, capericotos, caquetíos y jirajaras, poblaban los alrededores de los montes y serranías que circundaban la ciudad de Barquisimeto, capital actual del estado Lara. Según A. Perera (PERERA Alonso. Organización de Pueblos Antiguos de Venezuela, tomo I; Madrid, Imprenta Juan Bravo, 1964).

"La mayor parte fueron dóciles y se prestaron al trabajo en las encomiendas. Pero hubo un grupo que no se doblegó a los españoles.()...Ese fue el caso de los gayones. De carácter aguerrido y belicoso, estos indígenas perpetraban sin cesar robos en los caminos reales de los alrededores de Barquisimeto, por lo que se fue creando un clima de zozobra entre los pobladores [y se les acusaba de] ...estorbaban las comunicaciones entre Barquisimeto, el Tocuyo y Carora, las cuales tenían que hacerse en caravanas armadas, además varias veces intentaron contra Barquisimeto; [se vivían]...períodos de relativa tranquilidad y de recios ataques que tenían que refrenarse por las armas". (tI, 101). De igual manera, el mismo autor cita a los siguientes pueblos que se fundaron con Gayones: Humocaro Bajo, Humucaro Alto, Santa Rosa de Sanare, Santa Rosa de Acarigua, Chabasquen, Cerrillo de Santa Rosa, Bobare, etc....

10 "Los indios gayones, desde su conquista y la obediencia dada V.M., siempre han sido vasallos de mala ley, de ninguna voluntad a los españoles, ni inclinados a más trabajo que a vagar con el arco y flechas por los montes buscando caza, para sustentarse, sin haber labranza para mantenerse ni otra granjería. Las tierras de su naturaleza son intratables, de montañas y breñas ásperas, que sólo ellos entran...Hoy se hallan en las orillas del río de Barquisimeto, tres leguas de la ciudad, agregados a una misión de los religiosos capuchinos, que llaman Cerrillo de Santa Rosa, donde se les da pasto espiritual pero sin olvidar su mala naturaleza, saliendo a los robos y muerte que ejecutaban antes, aunque no con tantos daños, valiéndose de la astucia de recogerse a la misión antes de ser cogidos en los campos" (ARI, Santo Domingo 197 -A; citado por ARELLANO, Fernando, S.J. Una Introducción a la Venezuela Prehispánica. Culturas de las Naciones Indígenas Venezolanas. Caracas, Universidad Andrés Bello. 1986). Alfredo Jhann (JHAN Alfredo. Los aborígenes del occidente de Venezuela. Tomo II. Caracas, Monte Ávila Editores, 1973), señala que probablemente los gayones eran de filiación lingüística chibcha. 
"Además, los propios indígenas en permanente movilización, al recorrer montes y sabanas, difundieron por toda la jurisdicción de Barquisimeto la noticia de la nueva advocación" 11 . Desde el momento cuando, por equivocación, una escultura de la Divina Pastora fue enviada a la Iglesia de Santa Rosa de Lima en el pueblo de Santa Rosa del Cerrito, sacerdotes como el cura doctrinero Sebastián Bernal se dedicaron a promover la devoción hacia la Virgen María en su versión pastoril: La Divina Pastora de las almas.

En el caso de la narrativa oral que habla del origen de la imagen de Nuestra Señora del Rosario de Chiquinquirá, La Chinita, se dice que llegó a Maracaibo procedente de Colombia en 1709, era "una tablita que un barco había tirado al mar", y entre las olas sonoras y espumosas del mar "fue empujada a la orilla norte del lago de Maracaibo, donde una lavandera la encontró, la recogió, se la llevó para su casa y le dio el uso de tapa para una tinaja de agua"12, en ese espacio, a orillas del lago se consumó el milagro. El retablo de la "tablita", era una copia del cuadro del pintor Alonso de Narváez que Antonio Santana, jefe español del pueblo de Sutamarchán había mandado a pintar y que él mismo, cuando comenzó a deteriorarse, había enviado a su finca de Chiquinquirá (Colombia). El primer milagro se produce en 1578, cuando María Ramos, recoge el cuadro ya borroso, lo limpia y lo cuelga hasta que seis años después una india cristiana, llamada Isabel y su hijo Miguel, descubrieron el cambio que había dado el cuadro, estaba en el suelo despidiendo de sí un resplandor que inundaba toda la Capilla.

En Maracaibo (Estado Zulia) el milagro tiene algunas características parecidas: es una humilde mujer quien encuentra la imagen y descubre el 18 de noviembre de 1709 el resplandor que la "tablita" tenía y como habían aparecido en ella la imagen de la Virgen del Rosario de Chiquinquirá con San Antonio y San Andrés a los lados ${ }^{13}$. El culto a esta imagen comienza en una ermita construida en honor a San Juan de Dios, que fue luego transformada en capilla para la imagen de la virgen en $1712-1717^{14}$. Su culto se fue extendiendo, y en 1915 -16 se solicitó a su Santidad Benedicto XV su coronación, que se llevó a cabo un año después como patrona de la ciudad. Desde hace 300 años se conmemora, el 18 de noviembre la fiesta de Nuestra Señora del Rosario de Chiquinquirá, quien, fue primero la patrona del Saladillo, viejo barrio, donde comenzó a gestarse la ciudad de Maracaibo; formaba parte de su casco central hasta que fue demolido por una decisión presidencial en los años setenta para dar paso a la "modernización" de la ciudad; de igual manera, era y sigue siendo el espacio mítico ya que coincide con el lugar donde apareció Nuestra Señora del Rosario de Chiquinquirá. Más tarde la patrona de la ciudad de Maracaibo ${ }^{15}$ y hoy por hoy, es la patrona de los zulianos ${ }^{16}$.

Estas son dos de las experiencias religiosas católicas que convocan a mayor cantidad de feligreses. Sus ritos conmemorativos incluyen procesiones y peregrinaciones de

11 SUÁREZ, María Matilde/BETHANCOURT, Carmen. La Divina Pastora Patrona de Barquisimeto. Caracas, Fundación Bigott, 1996, p. 43.

12 BESSON, Juan. Historia del Estado Zulia. Tomo III. Maracaibo, Ediciones Banco Hipotecario del Zulia, 1973

13 BESSON, Juan. Historia del Estado Zulia. Tomo III. Maracaibo, Ediciones Banco Hipotecario del Zulia, 1973.

14 En la visita del obispo Martí a Maracaibo en 1774, reseñó que el templo de la ciudad contaba con cinco altares, en el altar habían cinco nichos y en el principal estaba ubicada Nuestra Señora del Rosario de Chinquiquirá.

15 Capital del Estado Zulia y segunda ciudad en importancia del país.

16 Los zulianos es el toponímico de los nacidos en el Estado Zulia, entidad federal situada en la región noroccidental de Venezuela, con $63.100 \mathrm{Km}^{2}$, la mayor extensión de la depresión del Lago de Maracaibo. 
las imágenes a los diversos municipios de cada uno de los Estados. En el caso del Estado Lara la peregrinación va desde el 14 de enero - día central de su celebraciónhasta el sábado anterior al domingo de Ramos y en el Estado Zulia, la peregrinación se inicia el último sábado de octubre e incluye procesiones a las parroquias y a los municipios, incluidos los lacustres, llega a su santuario días antes del día central de su conmemoración (18 de noviembre), la cual se extiende hasta el primer sábado de diciembre que se celebra "el día de la aurora" y la imagen regresa a su sitio en el altar de la Basílica.

A partir de las entrevistas realizadas a los devotos, es posible inferir que la focalización de esas prácticas y creencias son las dos advocaciones. El fervor hacia ellas y su acercamiento: a "Ella", la divina "Madre" y a las representaciones visibles (imágenes, cuadros, estampitas, oraciones, rosarios, otras), a las que le ofrecen y elevan algunas plegarias, oraciones, cantos, poesías, gaitas ${ }^{17}$, misas, novenarios, rosarios, flores, promesas, visitas a las iglesias que son consideradas los santuarios, así como también a aquellas iglesias donde las imágenes pernoctan.

Como consecuencia de los milagros y promesas, se llega a establecer una relación personal y profunda del devoto con la Virgen, que se verbaliza en la palabra de la "fe", entendida ésta como confianza; como saber que se puede contar con "ella" y que no le va a fallar, sobre todo en los momentos difíciles. Tal fe se vive especialmente en el terreno de los sentimientos y se expresa en los dones que ofrece el devoto como: rezar, ofrecer misas, pagar promesas, ir descalzo ya sea a la misa o a la procesión, vestirse de Nazareno y/o pastora, en el caso de la Divina Pastora, con manta wayuu ${ }^{18}$ en el caso de Nuestra Señora de la Chiquinquirá. También hacen peticiones como pedir por la salud, encontrar trabajo, por mencionar algunas. Las principales razones que exponen para explicar el porqué de su fervor y el asistir todos los años a visitarlas en las fiestas patronales, son las siguientes:

a) por ser "marianos de verdad, verdad": así como la socialización familiar o grupal modela al individuo, así también la socialización religiosa en la familia o en el pueblo modela al individuo más que la catequesis. Al preguntarle a los creyentes responden: "es la religión de mis padres, crecí en ella y porque desde la niñez la 'Divina Pastora' y/o 'La Chinita', han estado en nuestras casas, es nuestra patrona”. Es decir, la espiritualidad católica surgió en el seno del hogar y las siguientes generaciones han crecido con esa vivencia. Reinterpretación que han hecho a partir de su experiencia histórica en la "Iglesia de mis padres".

b) por los "milagros": porque "se tiene fe' y siempre son milagrosas. El "milagro" como un "hecho" extraordinario. Éste es para los devotos no sólo la posibilidad de satisfacer las necesidades imposibles de la cotidianidad, sino también como un signo

17 La gaita zuliana es un género musical que nace con las inquietudes republicanas en las primeras décadas del siglo XIX. En sus orígenes, se mezclaron cánticos religiosos y dicembrinos acompañados por la percusión de las tamboras, el furro (un derivado de la Zambomba), las maracas, la charrasca y el cuatro (guitarra de cuatro cuerdas). Se escribe en compás de 2/4 con trecillo de corcheas. Su estructura literaria esta conformada de versos octosílabos. Son tres versos y un estribillo. Hoy por hoy es uno de los géneros musicales particulares de la región zuliana.

18 La manta es el vestido que utilizan las mujeres wayuu, generalmente es una bata de algodón larga y enteriza, recogida debajo del busto. 
de bondad y de poder y el descubrimiento de un mundo trascendente o como 'otro mundo'; es decir, un verdadero acto sagrado, por tener carácter numinoso. Esto es, la irrupción "milagrosa" en la vida de los devotos que deja profunda huella.

c) solidaridad social: tanto la "Divina Pastora" como "Nuestra Señora del Rosario de Chiquinquirá" (la Chinita), son símbolos de la vieja solidaridad de los pueblos, manifestación que se hace presente en la devoción y en las nuevas solidaridades en la ciudad: la celebración de las "fiestas".

d) otro aspecto observado son las promesas: éstas no son sólo un pacto de reciprocidad con las deidades de darles algo a cambio de lo que se le pide, sino también un compromiso de honor al ofrecerles "algo" sin pedirle nada a cambio. En la observación que se realizó dentro de las respectivas iglesias (Santa Rosa de Lima y La Basílica Menor de San Juan de Dios y Nuestra Señora de Chiquinquirá), los participantes llevan velas, flores, escuchan misas, comulgan, rezan el rosario, se la pasan todo el día en la iglesia, asisten a la procesión, pero nunca dicen el porqué lo hacen. Sólo algunos comunican "si prometo, debo cumplir lo prometido". Sin embargo, la "promesa" es en la mayoría de los casos la aplicación al terreno religioso de la reciprocidad que constituye el lenguaje específico de expresar un compromiso personal completamente desinteresado hacia la deidad.

\section{II}

Cuando grupos humanos diferentes se ponen en contacto -sea cual sea la causase generan relaciones interétnicas, donde casi siempre se ponen en duda o flaquean la estabilidad y coherencia de los sistemas simbólicos correspondientes a los grupos implicados en la relación. En muchos casos elementos procedentes del sistema simbólico originario son rechazados, en otros son integrados, adaptados, reinterpretados o recreados, para preservar algo del sistema simbólico básico y fundamental. Esto trae como consecuencia, el tránsito de los códigos simbólicos entre los grupos y la reubicación de éstos en posiciones diversas.

En el caso que nos ocupa, estos dos cultos a la Virgen María, en dos advocaciones diferentes y asumida por sus creyentes como código identitario particular de cada una de las regiones, son resultado de procesos de relaciones interétnicas. Sea por razones históricas, por yuxtaposición de aspectos mitológicos, por sincretismo ${ }^{19}$ o por la diversidad de cultos a ese principio femenino, así como a la proliferación de imágenes que representan a la "madre humana" de la fecundidad que ha estado presente en la

19 Entendemos por procesos sincréticos "la formación, a partir de dos sistemas religiosos, de otro nuevo, cuyas creencias, ritos, formas de organización y normas éticas son producto del interacción dialéctica de los dos sistemas en contacto. El resultado de esa interacción dialéctica en los diferentes niveles del nuevo sistema religioso será, ya la "persistencia" de determinados elementos con su misma forma y significado, ya su pérdida total, ya la "síntesis" de otros elementos con sus similares de la otra religión, ya, finalmente, "la reinterpretación de otros elementos". De estos cuatro procesos (persistencia, pérdida, síntesis y reinterpretación), el último ha merecido mayor atención de parte de los antropólogos". (Marzal Manuel; "Sincretismo y mundo andino: un puente con el otro" En PORTILLA, Miguel (eds.). De Palabra y obra en el nuevo mundo. 3.- La formación del otro. Madrid, Siglo XXI editores y La Junta de Extremadura, 1993, p. 234. La reinterpretación puede ser definida no sólo como el proceso por el cual los antiguos significados se adscriben a los nuevos elementos o mediante el cual los valores nuevos cambian la significación cultural de las viejas formas, sino también cuando se le añaden nuevos significados. 
figura de la "Gran Madre". En este sentido los creyentes entienden la maternidad como una vinculación de los devoto-creyentes con la Virgen María por ser madre de "Cristo" y madre de ellos.

En estos dos espacios geográficos, las advocaciones de la Virgen - Madre pudieran entenderse como una resignificación de viejos códigos simbólicos de las deidades precolombinas a la fertilidad, pero llegó la Cruz conquistadora y misionera: "El pueblo que andaba a oscuras vio la luz grande... una luz brilló sobre ellos" ${ }^{20}$, y en dicha luz estaba representada la "Madre". Hay diferentes versiones y razones manifestadas por los creyentes-católicos-devotos para que estas deidades se hayan anclado dentro de dichos contextos y en el corazón de sus habitantes; en palabras de Alfonso Reyes ${ }^{21}$, "Un pueblo se salva cuando logra vislumbrar el mensaje que ha traído al mundo, cuando logra electrizarse hacia un polo, bien sea real o imaginario, porque de lo uno y lo otro está tramada la vida. La creación no es un juego ocioso. Todo hecho esconde una secreta elocuencia, y hay que apretarlo con presión para que suelte su jugo jeroglífico. ¡En busca del alma nacional!”.

Búsqueda centrada en dos aspectos, el primero en la necesidad de "creer en algo" diferente por haber perdido o haber sido arrebatadas sus tradiciones, sus valores y lo ofrecido no llena el vacío dejado, lo cual constituye un buen modelo de opio moderno. El otro aspecto, es que hubo sin lugar a dudas, relaciones de contacto entre las diferentes culturas: amerindias, española y africanas, en todas ellas había presencia de deidades femeninas. No olvidemos que la presencia de Diosas Madres aparecen altamente desarrolladas desde el Neolítico, por lo que se considera que la forma femenina es la más antigua; con lo que se descubre y ofrece una simbólica matricial de re-nacimiento, re-generación o vuelta a la vida.

La construcción del mito acerca de la virginidad de María y la exaltación de su maternidad divina, tiene una vinculación con los cultos dedicados a las Diosas y, particularmente, al de Artemisa (Diana), que representaba la amalgama de elementos religiosos persas y greco-romanos y en América, por qué no indígenas; probablemente, por esa razón, se ha hecho tan popular. De allí que se suele interpretar como la gran magia del "embarazo" o como magia de la "fertilidad-fecundidad" como elemento simbólico que la lleva a engendrar sin esposo. Desde esta perspectiva, "María" es la resignificación de la maternidad que se evidencia en el pronunciamiento de sus palabras proféticas en el Magnificat" “Mi alma alaba la grandeza del Señor/mi espíritu se alegra en Dios mi Salvador./ Porque Dios ha puesto sus ojos en mí, su humilde esclava,/ y desde ahora siempre me llamarán dichosa;/ porque el Todopoderoso ha hecho en mí grandes cosas./;Santo sea su Nombre!”.

Ahora, visto también desde los mitos amerindios ya sea el mito chibcha de la diosa "Bachue", que narra como la diosa hizo resplandecer la tierra, emergió de la laguna de Iguaque sacando consigo a su hijo, con quien bajó a la serranía, para posteriormente construir viviendas y fundar pueblos; cuando el niño creció se casó con él y llenó de gente la tierra. O los mitos wауиu donde la presencia de la mujer se expresa de diversas

20 Is. 9,1. La Biblia. Bogotá, Sociedad Bíblicas Unidas, 1994.

21 REYES, Alfonso. Carta de Alfonso Reyes en La Tierra del Faisán y del Venado, México, Edición CostaAmic, 1974, p. 9.

22 Lucas. 1. 46-49. La Biblia. Bogotá, Sociedad Bíblicas Unidas, 1994. 
maneras: a) en el mito de Mma, la tierra, preñada por Juya, la lluvia, de donde nacieron los wayuu; b) el de Wolunka, la mujer primigenia, cuya vagina dentada no permitía a los hombres unirse con ella y procrear a los wayuu, hasta que una pareja de hermanos le flechan la vulva tumbándole los dientes y haciéndola sangrar cuando se baña en la laguna de Wotkasainru, en la Alta Guajira,. De ahí el origen de la menstruación de las mujeres y el inicio del aprovechamiento de su capacidad procreadora; c) en el mito de las jóvenes que en el cerro de Makuira son enseñadas por las hembras de los animales a tejer los diseños de la fecundidad de la tierra y a cantar el fuego de sus ancestros.

En estos casos podemos observar arquetipos: el de la mujer madre y la mujeramante-madre, dedicadas a la procreación. En todas estas narraciones míticas se focaliza el símbolo de la fuerza de la fecundidad y de fertilización. Es decir el principio húmedo de la vida. De tal manera que "...el alumbramiento y el parto son las versiones microcósmicas de un acto ejemplar ejecutado por la tierra”; la madre humana no hace sino imitar o repetir este acto primordial de la aparición de la Vida en el seno de la tierra. En este sentido, aun cuando se desconozca acerca de la fisiología del esperma y el óvulo, está presente el proceso de la fecundación; la esperma era una semilla, como la de Onán ${ }^{23}$, que desparrama la suya, según la Biblia. La vagina era la tierra que la incubaba. La fertilidad de la mujer, era equiparada con la tierra, donde la semilla es alimentada, crece y da frutos. En este sentido, la fertilidad misma confería cierto contacto milagroso y divino, como aún algunos lo ven reflejado en el rostro de cualquier mujer embarazada. De manera tal, que todo el misterio de "María" reposa en una palabra: "SÍ" y fue a través de esta expresión afirmativa que se convirtió en "Madre". Y es así como desde la modernidad, la mujer "María" se ha hecho partidaria a la vez de la vida y de la libertad de elección.

\section{III}

Estas imágenes, en aquellos lugares donde se les rinde culto, se han convertido en un símbolo, no sólo religioso sino parental e identitario. La distancia intrapersonal en la transacción cotidiana de los actores ordena simbólicamente su mundo interior, pero como factor para expresar lo que ven y lo que sienten en su interioridad, necesitan del aspecto creativo del lenguaje y esto sólo lo podrán expresar a partir del habla para comunicar el o los eventos estructurados, que involucran la reciprocidad. Es decir, la participación mutua entre el yo/tú. Pero el elemento vital a todas estas aproximaciones es el paso desde la focalización en el texto hasta la focalización en el evento comunicativo. El texto tanto oral como escrito, permite conocer las relaciones establecidas entre el yo (creyente)/tú (el otro con quien se habla) como aspectos de base en la interacción ${ }^{24}$. La cual puede resumirse en tres acciones: desear, comunicar y participar. Este yo-tú viene siendo la clave del nivel de acción que no pueden definirse, sino en relación con el discurso (lo expresado), en correspondencia con una temática que los antecede y determina, pero que a su vez, lo centraliza en el fervor, prácticas y creencias acerca de la Divina Pastora en Santa Rosa del Cerrito en el estado Lara y 1986. 
Nuestra Señora del Rosario de Chiquinquirá (China, Chinita, Chinata) en Maracaibo estado Zulia. Deidades que son concebidas como expresión histórica e identitarias, como representación del sí mismo.

La competencia textual de las narraciones de los creyentes está centrada en la capacidad de captar o asignar coherencia a sus expresiones, independientemente de la forma lingüística en que se presenten, ya que el hablante tiene su propia competencia. En estas creencias, el misterio de lo femenino y de la vida se convierte en símbolo y se podría interpretar como el símbolo del retorno, de la llegada y de la partida, del nacimiento y de la muerte, la ascensión y la decadencia, la aparición y la desaparición. Esto podría significar el gran misterio de fuerzas sobrenaturales e inexplicables que lleva a los devotos a expresar lo que ellos experimentan ante la presencia de estas dos deidades:

“¡Siento alegría,...y la visito Yo siento que ella es un símbolo de Barquisimeto. Y si yo me voy por algún motivo de aquí me llevaría a la Divina Pastora" (Rosa Castro; Barquisimeto, 03/04/09).

"Soy muy creyente. Es nuestra patrona, nuestra madre. Hace 31 años que le tengo mucha fe. La veo con mucho amor. La veo como 'Madre' que me salvó la vida. Vengo por mi salud y la de todos. Es algo especial aquí adentro" (Rosa García; Agua Grande, 14/01/2008).

"La Divina Pastora es para nosotros lo más grande que podemos tener. Es la madre y lo domina todo. Cada día nos sentimos más apegados a Ella. Yo le pido por mi salud. Es lo más grande en esta población”. (Mercedes Yánez, Santa Rosa del Cerrito; 11/01/2008).

"Estaba enfermo y en mi recuperación asumí la fe mariana y la presencia de la Madre Todopoderosa y mi madre terrenal fue vital en mi curación; eso fue un abrazo que ambas se dieron y me ayudó a sanar rápido. La Virgen de Chiquinquirá me curó" (Omar Paz; noviembre 2007).

"Siento de verdad que la Virgen de Chiquinquirá nos hizo un gran milagro...Nuestra devoción viene desde hace muchos años, yo le tengo a la Virgen un altar en la entrada de mi casa, y siempre que puedo viajo a Maracaibo a visitarla” (Carlos Martínez; octubre 2008).

"En el octavo round perdí el dominio de la pelea, estaba desconcertado, me encomendé a la Chinita, prometiéndole un guantecito de oro si ganaba, me recuperé y gané la pelea" (Lorenzo Parra; 6 de diciembre 2007).

En consecuencia, en esa vinculación con el pasado y con el presente, el creyente trae a su memoria eventos o narrativas acerca de sucesos acaecidos en su cotidianidad ${ }^{25}$, para ello establecen relaciones, detallan lo que han vivido, aportan conocimientos compartidos y pueden desplazarse a partir del pasado, volver al presente y proyectarse al futuro. Es decir, pueden, expresar los contenidos en la medida en que el relato contado avance en un tiempo determinado dándole la debida coherencia y conformación a la trama en lo referente a los sucesos vividos. 
En la resemantización de estas figuras religiosas en el mundo de la Venezuela de hoy, sigue estando presente "el ser madre" como uno de los valores. Allí existe una tendencia a la matrifocalidad: “...es tanto un patrón cultural como una respuesta también, en caso de ser necesario, al decaimiento y privación de los hombres de menos recursos y acceso positivo a los dominios políticos y administrativos de la sociedad; en consecuencia, con un rol menos efectivo y de mayor dificultad y privación en el ámbito doméstico." ${ }^{26}$. Esta noción describe el rol fundamental que la mujer, ya sea la madre, la hermana, la abuela, la madrina, la tía, la esposa y/o compañera tienen, sin atender a clase social determinada. Ella se convierte en el centro del grupo doméstico; lo que permite que tengan cierta autoridad y libertad registrada. Es ella la que prácticamente ejerce la autoridad de aprobación decisiva entre la descendencia. Esta situación es consecuencia de que más del $42 \%$ de la población venezolana proceden de familias monoparentales, constituidas por mujeres solas que ejercen el doble rol de padre y madre a la vez; lo que produce un vínculo con lo materno como figura fundante que en casi todas las regiones del país, se traduce en la divinización de la Virgen - María que se convierte en un referente identitario, donde se vinculan símbolos, tanto de la madre celestial como de la madre terrenal. La madre temporal así como la Virgen María, en estas dos advocaciones cuidan, protegen, nutren, aman, perdonan, se sacrifican por... etc. Los siguientes discursos son un ejemplo de dicha situación:

- "No hay dolor ni decepción que la existencia descuadre cuando se tiene una madre que nos da consolación. Es como si el corazón de la virgen nos hablara cuando sonríe su cara y nos da su bendición.

Cuando habla mamá el patio florece cada planta crece como si tuviese mas luz y humedad refresca la ciudad sus ramas de vida los pájaros anidan el dolor se olvida pues la vieja está. Cuando habla mamá el amor nos canta desde su garganta un arrullo de cuna y un himno de paz parece que nos da su consejo amado el inmaculado y noble corazón de la Chiquinquirá". (Gaita: Cuando habla mamá. Letra y Música Víctor Hugo Márquez).

- "Chinata lo que yo anhelo es tu dulce bendición y le des la redención a este país que queremos para que juntos logremos la paz, la alianza y la unión”. (Gaita: Con el alma emocionada. Letra y Música Neguito Borjas. Canta Danelo Badell y Neguito Borjas).

-“Estoy recién operado del corazón... fue una operación de corazón y muy riesgosa...Yo tengo un gran fe y le pido a mi madre, madre de Dios y mía la Divina Pastora me ayude a salir de esta situación...Yo se que la Divina Pastora me sacará de esto. Nosotros somos una familia como toda familia venezolana: unida pero a veces con algún problemita, pero todos unidos salimos adelante.. Y hoy también con los problemas nuestros y de toda Venezuela...unidos vamos a salir... yo me debo a mi tierra a mi patria chica de Barquisimeto y a mi patrona la Divina Pastora". (Jesús Maurice, Barquisimeto 11/01/08). 
- "Para nosotros es Todo. Para nosotros es la virgen y nuestra madre, aquí en Santa Rosa es difícil conseguir un santarroseño que jamás le haya pedido un favor a la Divina Pastora y que no se le haya concedido. La consideramos como una virgen sumamente milagrosa; tenemos siempre la fe depositada en ella y por supuesto la adoración que le tenemos como una madre espiritual. Pues como le venía diciendo la Divina pastora es nuestra madre, nuestra guía la esperanza" (Óscar Arena, Barquisimeto; 03/04/09).

En estas narrativas los creyentes-devotos en forma oral así como otras, escritas o cantadas (gaitas) promueven un relación parental que les vincula con las deidades. Ese yo/tú, está fundamentado por la presencia del lenguaje. De tal manera que los devotos cuentan su historia, la viven, la sustentan y la recuerdan. Cada uno en su singularidad es un $<<$ yo-aquí-ahora $>>$ que han ido construyendo en el transcurso de su cotidianidad, en su espacio de "estar aquí" que es su ser histórico y que lo lleva a contar sus vivencias por ser "sujetos de dicho discurso con significado directo donde cada elemento de la forma está impregnado de valoraciones sociales vivas" 27

- "Para nosotros los zulianos y los gaiteros es un privilegio y un honor cantarle a la Chinita, más yo que soy mariano por convicción y cercanía, y ella es el amor de mis amores, es la elevación total, el clímax total de satisfacción, de espiritualidad, de gozo" (Gustavo Aguado, 22/11/08)

- "Ella significa para mi la presencia de Dios, de Jesucristo. Yo la veo con mucho amor y entusiasmo y la veo como madre que me salvó la vida". (Oscar Vargas, 11/01/2008)

-"Madre solo hay una que merece la fortuna de toda la humanidad Madre es sol y luna como ella ninguna pureza amor y bondad" (Gaita: La Madre de Cardenales del Éxito).

El desplazamiento semántico de la figura femenina en estos casos tiene un doble sentido: de la Virgen, en sus dos advocaciones -a la madre terrenal y de ésta a la Virgen-. Las madres son hacedores de todo, son "perfectas" y en la soledad del ejercicio de su maternidad-paternidad le otorgan al padre ausente un poder simbólico y la Virgen María es Todopoderosa, se le pide y encomienda la vida así como el perdón de los pecados. En el contenido de los discursos citados se detecta cuán importante es para los creyentes el grado de efectividad hacia la "Madre" imaginada y a la madre terrenal, y a la vez, se observa la exigencia de dar a conocer la presencia concreta en cuanto a la verificación y el testimonio total de las peticiones cumplidas.

27 BAJTín, Mijail M. Problemas de la poética de Dostoievski. México, Fondo de Cultura Económica. México. 1986. 